\title{
Thoracic inlet compression due to amiodarone induced goitre
}

\author{
A. Samanta, G.R. Jones ${ }^{1}$, A.C. Burden and W.W. Barrie \\ Leicester General Hospital, Leicester LE5 4PW and 'Leicester Royal Infirmary, Leicester LE1 5WW, UK.
}

\begin{abstract}
Summary: We report a case of amiodarone induced toxic goitre, presenting with thoracic inlet obstruction which required surgical intervention. Though thyrotoxicosis caused by amiodarone is recognised, to our knowledge thoracic inlet compression has not been previously described.
\end{abstract}

\section{Introduction}

Since its initial marketing in Belgium in 1967, amiodarone has been extensively used as an antiarrhythmic drug. Despite its excellent properties in the treatment of resistant cardiac dysrrhythmias, it is not without serious side effects, and these have been recently reviewed by McGovern et al. (1983). Marcus et al. (1981) have noted a very small proportion of patients treated with amiodarone to develop mild and diffuse thyroid enlargement, but none of these has caused pressure symptoms or warranted surgery.

\section{Case report}

A 60 year old man with ischaemic heart disease and euthyroid both clinically and biochemically (thyroxine ( $\left.\mathrm{T}_{4}\right) 82 \mathrm{nmol} / \mathrm{l}$; normal $55-150 \mathrm{nmol} / \mathrm{l}$ ) was admitted in April 1981 for recurrent supraventricular tachyarrhythmias resistant to conventional therapy, and started on amiodarone. A chest X-ray before starting therapy showed minimal cardiomegaly but there was no evidence of thyroid enlargement, and no goitre was felt on physical examination. A maintenance dose of $200 \mathrm{mg}$ of amiodarone per day was used. Eight months later a smoothly enlarged thyroid with clinical thyrotoxicosis was noted. Serum $\mathrm{T}_{4}$ was $212 \mathrm{nmol} / 1$ (normal $55-150 \mathrm{nmol} / \mathrm{l}$ ) and triiodothyronine $\left(\mathrm{T}_{3}\right)$ was $2.7 \mathrm{nmol} / 1$ (normal $0.8-2.5 \mathrm{nmol} / \mathrm{l}$ ). A thyrotrophin (TSH) releasing hormone (TRH) stimulation test showed a flat TSH response. Thyroid antibodies were negative. Two months later, he developed symptoms of progressive dyspnoea and mild dysphagia. An Xray of the thoracic inlet showed displacement of the

$\overline{\text { A. Samanta, M.D., M.R.C.P.; G.R. Jones, M.B., M.R.C.P.; }}$ A.C. Burden, M.D., M.R.C.P.; W.W. Barrie, M.D., F.R.C.S.

Correspondence: Dr A. Samanta, Leicester General Hospital, Gwendolen Road, Leicester.

Accepted: 8 March 1984 trachea due to a diffusely enlarged thyroid gland. Amiodarone was stopped and digoxin and verapamil substituted. Over the next four months there was regression in the size of the goitre, and improvement in his symptoms. Unfortunately, the supraventricular tachyarrhythmia was not effectively controlled and amiodarone was re-started in July 1982. Over the next 6 months a progressive increase in the size of the goitre was again noticed. At the same time he became thyrotoxic, with a recurrence of dyspnoea, dysphagia and stridor. Upper gastrointestinal endoscopy and upper airway examination were normal. Amiodarone levels ranged between $1.0-1.7 \mathrm{mg} / 1$ (therapeutic range usually between 1-2 mg/1 respectively). Amiodarone was again stopped, and he became clinically and biochemically euthyroid, but the goitre did not regress and due to worsening pressure symptoms he required subtotal thyroidectomy in June 1983. At no stage did he receive any antithyroid drugs. At operation there was a large goitre with marked retrotracheal extension. The weight of the gland removed was $82 \mathrm{~g}$. Histology showed multiple follicles of varying size filled with colloid, some showing peripheral vacuolation fibroses and hyalinization of the stroma, and areas of flattening of the thyroid parenchyma.

\section{Discussion}

Amiodarone contains $75 \mathrm{mg}$ of organic iodine per $200 \mathrm{mg}$ of drug, which is the usual daily maintenance dose. Savoie et al. (1975) initially described the phenomenon of iodine-induced thyrotoxicosis as a complication of therapy, and more recently Harris et al. (1983) have discussed this as a side effect of long term amiodarone therapy. Belshaw \& Becker (1973) have proposed that iodine may cause direct thyroid injury in animals, akin to thyroiditis, and this may be one of the mechanisms of amiodarone-induced thyrotoxicosis. Alternatively, the drug may cause a 
failure of the normal homeostatic regulation of the thyroid gland (Jonckheer, 1981). The incidence of thyroid abnormalities, as noted by Marcus et al. (1981), has been between $2-4 \%$ and approximately half of those with hyperthyroidism also have a small goitre. This usually regresses with cessation of therapy.

Our patient developed a goitre and hyperthyroidism directly related to amiodarone therapy. Of particular interest are the marked pressure symptoms associated with this, and compression of the structures of the thoracic inlet severe enough to require surgery. Currently, there is very little available information on the histology of the human thyroid in relation to

\section{References}

BELSHAW, B.E. \& BECKER, D.V. (1973). Necrosis of follicular cells and discharge of thyroidal iodine induced by administering iodine to iodine-deficient dogs. Journal of Clinical Endocrinology and Metabolism, 36, 466.

HARRIS, L., McKENNA, W.J., ROWLAND, E., HOLT, D.W., STOREY, G.C.A. \& KRIKLER, A. (1983). Side effects of long term amiodarone therapy. Circulation, 67, 45.

JONCKHEER, M.H. (1981). Amiodarone and the thyroid. A review. Acta Cardiologia, 36, 199.

MARCUS, F.I., FONTAINE, G.H., FRANK, R. \& GROSGOGEAT, Y. (1981). Clinical pharmacology and therapeutic applications of the antiarrhythmic agent, amiodarone. American Heart Journal, 101, 175. amiodarone. Sloan et al. (1983) have described a case of thyroid tumour formation. In our patient, increased $>$ colloid with peripheral vacuolation is consistent with $\stackrel{\mathbb{Q}}{\varrho}$ hyperthyroidism but the interspersed areas of fibrosis $\stackrel{.}{.}$ is more like a thyroiditis. It is possible that following a $\vec{\Rightarrow}$ period of over-activity due to toxic injury, the gland may subsequently become underactive, as happens in thyroiditis. Hypothyroidism seen with amiodarone may be associated with a goitre and theoretically compressive symptoms may arise in this situation also.

In conclusion we would like to state that the effects in of amiodarone on the thyroid are diverse and complex, $\vec{\circ}$ and should be borne in mind in anyone on long term therapy.

McGOVERN, B., GARAN, H., KELLY, E. \& RUSKIN, J.M. خ (1983). Adverse reactions during treatment with $\vec{\omega}$ amiodarone hydrochloride. British Medical Journal, 187, î 175.

SAVOIE, J.C., MASSIN, J., THROMOPOULOS, P. \& LEGER, F. (1975). Iodine induced thyrotoxicosis in apparently normal thyroid glands. Journal of Clinical Endocrinology and Metabolism, 41, 685.

SLOAN, P.J.M., SINGH, S.P., BEVAN, P.G. \& GEARTY, J. $\stackrel{\overline{\widehat{\rho}}}{\supset}$ (1983). Adverse reactions during treatment with amiodarone hydrochloride (letter). British Medical Jouß nal, 287, 612. 